\title{
EPINEPHRINE SENSOR DEVELOPED ON MWCNT MODIFIED REDOX BEHAVING METAL COMPOSITE ELECTRODE
}

\author{
G. Sivasankari ${ }^{1} *$, S. Boobalan ${ }^{2}$, P. Mekala ${ }^{1}$ and S. Gowri ${ }^{3}$ \\ ${ }^{1}$ Department of Chemistry, Cauvery College for Women, \\ Thiruchirappalli- 620 018, Tamil Nadu, India \\ ${ }^{2}$ Chemistry Department, V.S.B. Engineering College, Karur-639 111,Tamil Nadu, India \\ ${ }^{3}$ Department of Physics, Cauvery College for Women, \\ Thiruchirappalli- 620 018, Tamil Nadu India \\ *E-mail: sivakspm@gmail.com
}

\begin{abstract}
In current years, surface modification of electrodes using the assorted electroactive medium is an engrossing sector of examine in electrochemical sensors. Sensors have eliminated leisurely preparation with the use of luxurious reagents, and have provided stumpy outlay analytical tools. Apart from, these sensors offer innumerable applications in food analysis, environmental monitoring and clinical diagnosis.

This work demonstrates the growth of sensors using electrochemical method based on Multiwalled Carbon Nanotubes (MWCNT)/cysteamine(Cys)/Nickel Hexacyanoferrate (NiHCF) nanocomposite (MWCNT/Cys/NiHCF) modified graphite electrode for detecting Epinephrine in $0.1 \mathrm{NaNO}_{3}(\mathrm{pH} 7)$ using voltammetric studies. The modified graphite composite electrode (GCE) prepared using depositing of $\mathrm{Ni}$ on MWCNT/Cys/GCE surface by electrodepositing nickel hexacyanoferrate (NiHCF). The electrode properties were examined by UV-visible, HRTEM and FTIR. The sensing performance of modified electrode exhibits towards the detecting Epinephrine (EP) from the range of $0.3 \mu \mathrm{M}$ to $4.1 \mu \mathrm{M}$ with the limit of the detection is $0.0211 \mathrm{nM}$.
\end{abstract}

Keywords: MWCNT/Cys/NiHCF, Epinephrine, Composite electrode, Sensor, Cysteamine

(C) RASĀYAN. All rights reserved

\section{INTRODUCTION}

Epinephrine also is known as adrenaline, synthesized from the gland of adrenalin the creature's body. One of the most significant hormones is released in the effect of twinge, dread, and antagonism. It's also acting as a brawl hormone provides hasty energy through catabolism of glycogen tissue. It's metabolized with oxidase of monoamine to 3,4-dihydroxyphenylglycol aldehyde.

EP released in retort to stress as well as enlarge the blood vessels of peripheral as a result cause gratis flow of blood furthermore It's worn as crisis healthcare medication in the cardiac seize, asthma, and sepsis. The squat concentration of EP is usually present in the body, but the level which is present in plasma is prominent in diverse physiologic circumstances, the same as at numerous disease, also at stress situation. The anomalous level of EP can escort to difficult possessions like Parkinson's disease. ${ }^{1-4}$

A study on nanomaterials skill is developing the interest of researchers in the entire world. Developments to be a creature ended to progress the properties of the material to find different precursors to provide enviable things on materials. An assortment of nanostructures has been proved to conclude their characteristics with the possible applications in sensors as well as biosensors. ${ }^{5-9}$ The morphology of the carbon-based nanomaterials include nanorods, nanotubes (CNT), nanoparticles, nanofibers, metallic nanowires, graphene, nanodots, metal-based, nanocomposite and carbon black. ${ }^{10-16}$

The nanotubes of carbon are really revamped structural characteristics of composites. Owing to its electrical conductivity, CNTs as well have relevance to produce the economical anti-static composite materials, electronics and solar cells.

The prettiness of electrochemical (EC) techniques is to exploit a custom-made chemically modified electrode (CME) intended for perceptive and discerning applications. The electrode can itself execute

Rasayan J. Chem., 12(4), 1985-1991(2019)

http://dx.doi.org/10.31788/RJC.2019.1245430

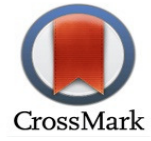


while a reactant to thrust (reduction)/remove (oxidation) electron inside the retort, it would not be projected in spectroscopic methods. In permutation amid CMEs, It is also crooked into imperative applications into synthetic organic also material depiction. Towards the preparation of CME, mainly a bony film of preferred chemical be each vault or encrusted on the surface of the electrode to bestow enviable properties of film insensibly with chemically premeditated manners. CME's most distinguishable features are electrocatalytic property to utilized into electroanalytical chemistry. ${ }^{17}$

In this present work explained the exclusive characters of CNT formulate them enormously gorgeous for amperometric sensors. The snatched progress of novel nanotechnology and nanomaterials has provided numerous opportunities for electroanalysis. Also, MWCNT/Cys/NiHCF modified electrodes provide very high sensitive towards Epinephrine determination.

\section{EXPERIMENTAL}

\section{Material and Methods}

While the chemicals were purchased from commercial suppliers. Graphite powder and MWCNTs at Aldrich (1-2 $\mu \mathrm{m} \& 5-10 \mathrm{~nm}$ ), (Aldrich, Steinheim, Germany). Epinephrine purchased in Himedia (P) Ltd, India, $\mathrm{NiCl}_{2}, \mathrm{~K}_{4}[\mathrm{Fe}(\mathrm{CN})]_{6}$ were purchased from Merck (Mumbai, India). For electrochemical technique, (DDW) Double distilled water was used. $0.1 \mathrm{M}$ of $\mathrm{NaOH}$ and $\mathrm{HCl}$ are used to maintain the $\mathrm{pH} .20 \mathrm{mM}$ of cysteamine was equipped by DD water and $0.01 \mathrm{M}$ of nickel solution equipped in ethanol. Potassium ferrocyanide $(0.02 \mathrm{M})$ with $\mathrm{NaNO}_{3}(0.1 \mathrm{M})$ was used as an electrolyte to coordinated nickel ion as hexacyanoferrate by derivatization.

\section{Purification and Functionalization of Multiwall Nanotubes}

The refinement of CNTs is a necessary stride with the preparation of functionalized nanotubes. Thus the entire MWCNT samples are purified ahead of chemical modification. During an emblematic experiment, sonication method is used to clean MWCNTs followed through extensive stirring, filtered, centrifuged and rinse systematically with DDW. Later than washing, the obtained black solid heated by $225^{\circ} \mathrm{C}$ for 15 h. This was recurring at $325^{\circ} \mathrm{C}$ for $2 \mathrm{~h}$ as well as $350{ }^{\circ} \mathrm{C}$ for $1.5 \mathrm{~h} .^{18}$

\section{Preparation of Modified Electrode}

To make the electrode, $1.5 \mathrm{mg}$ of MWCNT is detached in $3 \mathrm{~mL}$ of ethanol by agitation using an ultrasonic condition for $60 \mathrm{~min}$. To get a homogeneous suspension of MWCNTs. $4 \mathrm{~g}$ of Graphite powder was mixed with $1 \mathrm{~g}$ of wax and then make it as a composite electrode. The electrode washed well before used. This electrode was dipped for 20 minutes in $20 \mathrm{mM}$ of cysteamine and $5 \mathrm{~min}$ for $0.01 \mathrm{M}$ of nickel solution. The surface adsorbed $\mathrm{Cys} / \mathrm{NiHCF}$ graphite composite electrode was dipped with these nanotubes for $10 \mathrm{~min}$ at room temperature.

\section{RESULTS AND DISCUSSION \\ HRTEM images of MWCNT/Cys/NiHCF Modified Electrode}

MWCNTs Dispersed on NiHCF milieu is the most important one for the preparation of composite. HRTEM images (Fig.-1) of MWCNT/Cys/ NiHCF composite be recorded. Arbitrary distribution of MWCNTs be pragmatic and showed (Fig.-1A) to the MWCNTs be unvaryingly dispersed on the matrix. The size of the electrode was observed from $35-50 \mathrm{~nm}$.
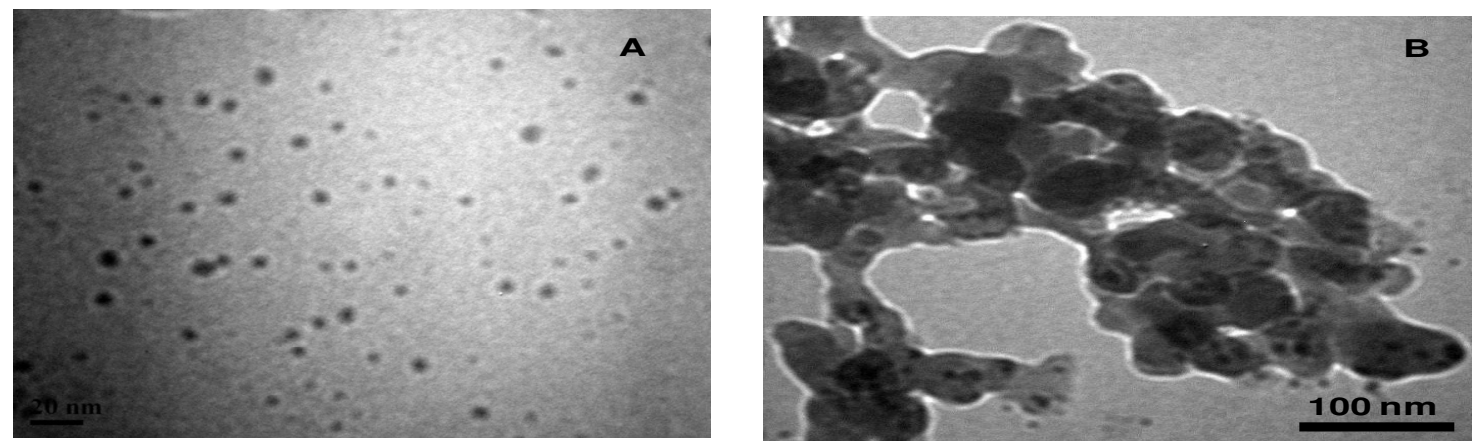

Fig.-1: HRTEM Images of MWCNT/Cys/NIHCF Electrode 


\section{FTIR Spectroscopy}

FTIR was recorded for functionalized MWCNT through Cys/NiHCF. Figure-2 shows the spectra for pure MWCNT and MWCNT/ Cys/NiHCF composite. For the MWCNT sample (curve a), the peaks observe at 1662 and $1528 \mathrm{~cm}^{-1}$ is denoting carboxylic acid groups (-COOH) stretching and oxidized CNT, respectively. FTIR spectra of MWCNT with Cys/NiHCF (curve b) are around 3082, 1418, 1112, 1109, and $822 \mathrm{~cm}^{-1}{ }^{19}$. These stretching inveterate that MWCNTs were effectively reacted among Cys/NiHCF to form Cys/NiHCF -MWCNTs composite.

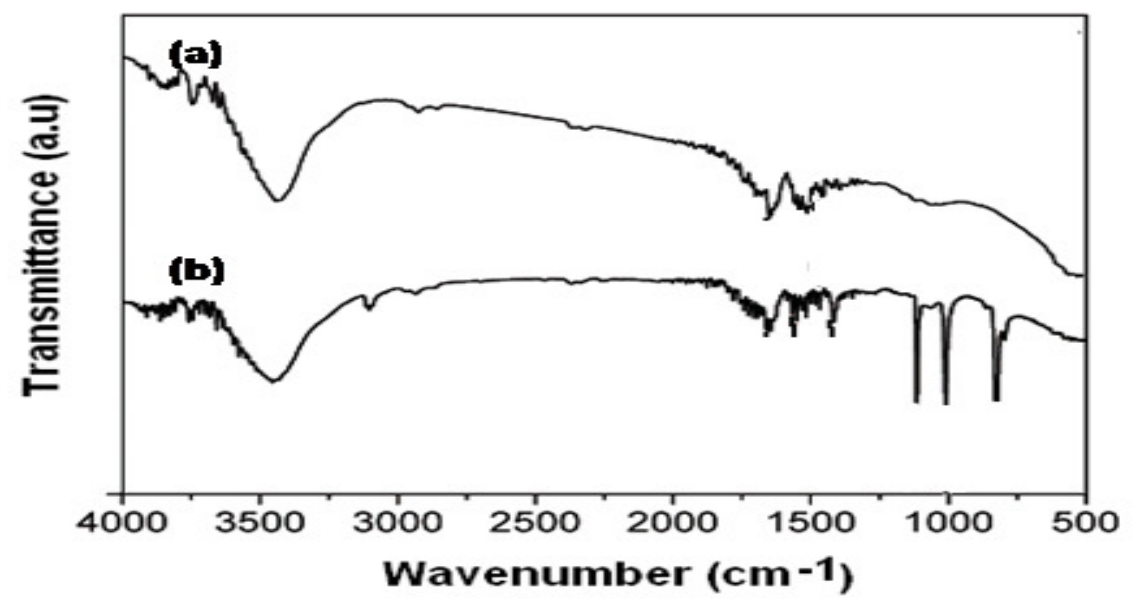

Fig.-2: FTIR Spectra (A) Pure MWCNT and (B) Cys/Nihcf Functionalized MWCNT Composite

\section{UV- Visible Spectroscopy}

Figure-3 shows the UV-Visible spectra of MWCNT/Cys/NiHCF modified electrode. The wavelength of $460 \mathrm{~nm}$ denotes NiHCF nanoparticle and 620nm represents CNT.

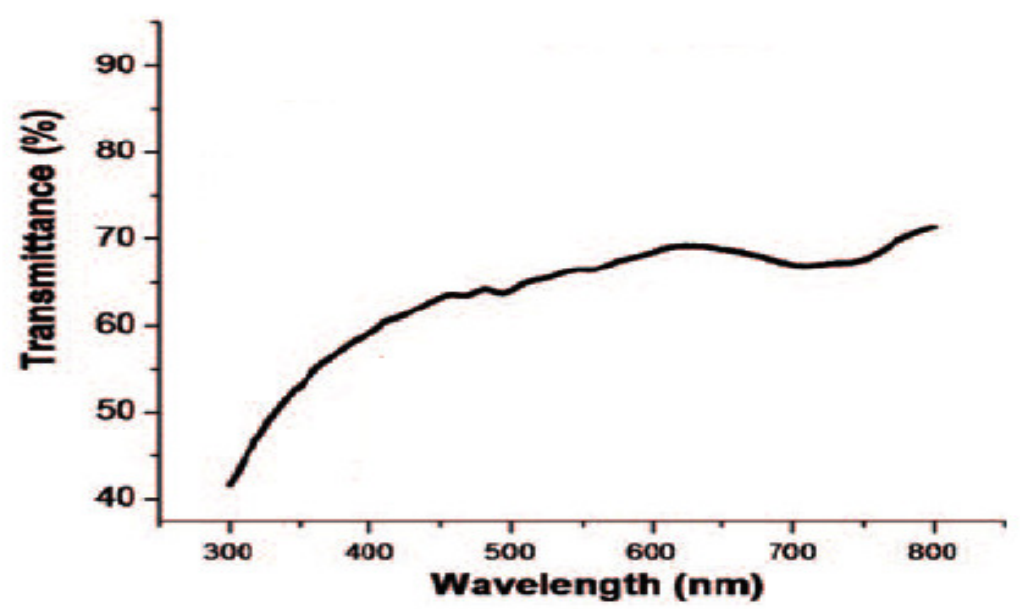

Fig.-3: UV- Visible Analysis of The Electrode

\section{Cyclic Voltammetric Studies of MWCNT/Cys/NiHCF Electrode}

The cyclic voltammograms (Fig.-4) of different modified electrodes were observed with the potential array of 0 to $0.6 \mathrm{~V}$ at $\left(\mathrm{pH} \mathrm{7)} 0.1 \mathrm{M} \mathrm{NaNO}_{3}\right.$ solution. The bare electrode doesn't observe any redox peak (curve a, background current of MWCNT/Cys/NiHCF electrode (curve d) is actually larger than the bare electrode, It's confirmed that surface of the modified electrode is extensively enhanced with the help of MWCNT. 


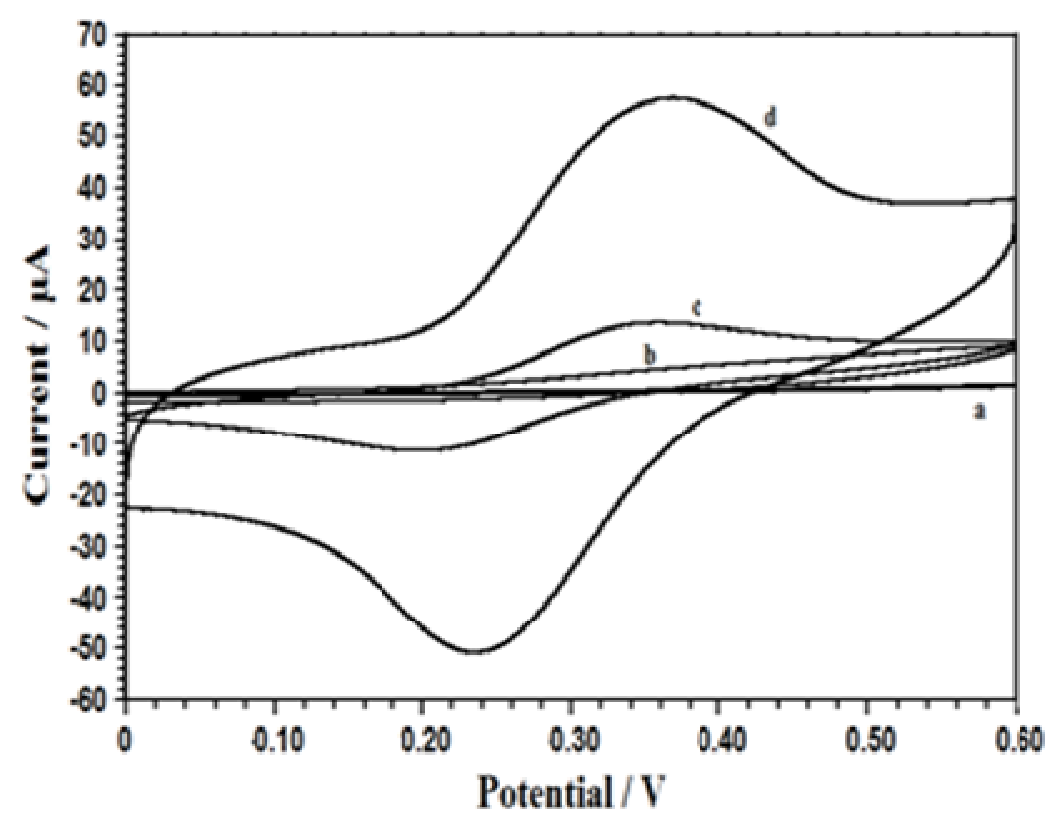

Fig.-4: Cyclic Voltammetric Response of Curve (a) Bare, Curve (b) Bare With CNT (c) Bare With Nihcf And (d) MWCNT/Cys/Nihcf Modified Matrix

\section{Effect of Scan Rate Variation}

Various scan rate study was done on the MWCNT/Cys/NiHCF electrodes, starting from $10 \mathrm{mV} / \mathrm{s}$ to 100 $\mathrm{mV} / \mathrm{s}$ were recorded using cyclic voltammetry are not shown in fig. That the peak-to-peak separation increases with an increase in scan rates. The smaller peak separation indicates that the electron transfer and counter ion transport are fast and exhibit ideal behavior. The plot of peak current Vs the scan rate's square root shows linear dependence suggesting, redox reaction be diffusion controlled.

\section{Analytical Utility of the Modified Electrode}

As the MWCNT/Cys/NiHCF electrode exhibit excellent stability and reproducibility, attempts have been made to use this electrode for amperometric sensor and electrocatalytic oxidation of important analyte Epinephrine and the results are presented in following paragraphs. The feasibility of using the MWCNT/Cys/NiHCF electrode for the Epinephrine sensor was investigated through oxidizing Epinephrine with the modified electrode. A known concentration of Epinephrine $\left(2.03 \times 10^{-3} \mathrm{M}\right)$ was taken and subjected to electrocatalytic oxidation. The oxidation current was measured by varying the concentration of Epinephrine. The anodic current produced by the catalytic oxidation of Epinephrine increases linearly with the amount of Epinephrine added which is shown in (Fig.-5). A calibration plot was drawn with a concentration of Epinephrine Vs. oxidation current. The oxidation current increase proportionally with an augment in the amount of Epinephrine and the plot was linear in the range of 2.03x $10^{-7}$ to $2.46 \mathrm{x} 10^{-3} \mathrm{M}$. The mechanism of the oxidation of EP at the modified electrode is shown in Scheme-1.

\section{Hydrodynamic Voltammetry (HDV)}

HDV for the catalytic oxidation was performed to investigate the analyte, use of the modified electrode in flow systems. Figure-6 shows that the HDV obtained for (curve a) bare electrode and MWCNT/cysteamine/NiHCF electrode (curve b) respectively.

It is explained that the curve at the modified electrode (curve d) has enhanced the current response on Epinephrine sensor at a reduced potential. But with the bare electrode (curve c) poor response to Epinephrine oxidation was observed. Also, stable voltammetric behavior in stirred condition shows applicability in flow systems. 
RASĀYAN J. Chem.

Vol. 12 | No. 4 |1985 - 1991| October - December | 2019

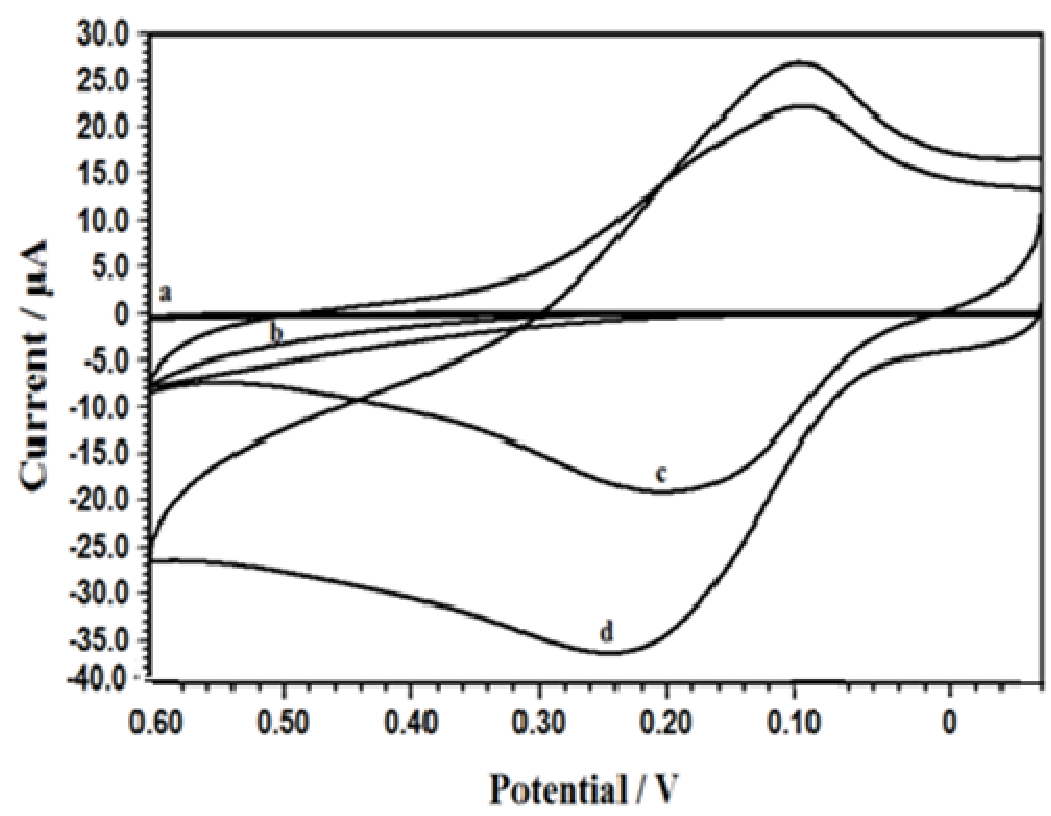

Fig.-5: Cyclic Voltammetric Response of (a) bare, (b) $2.03 \times 10^{-7} \mathrm{M}$ of Epinephrine at Bare (c) Modified Matrix (d) $2.03 \times 10^{-7} \mathrm{M}$ of Epinephrine at MWCNT/NiHCF Modified Electrode at $20 \mathrm{mVs}^{-1}$

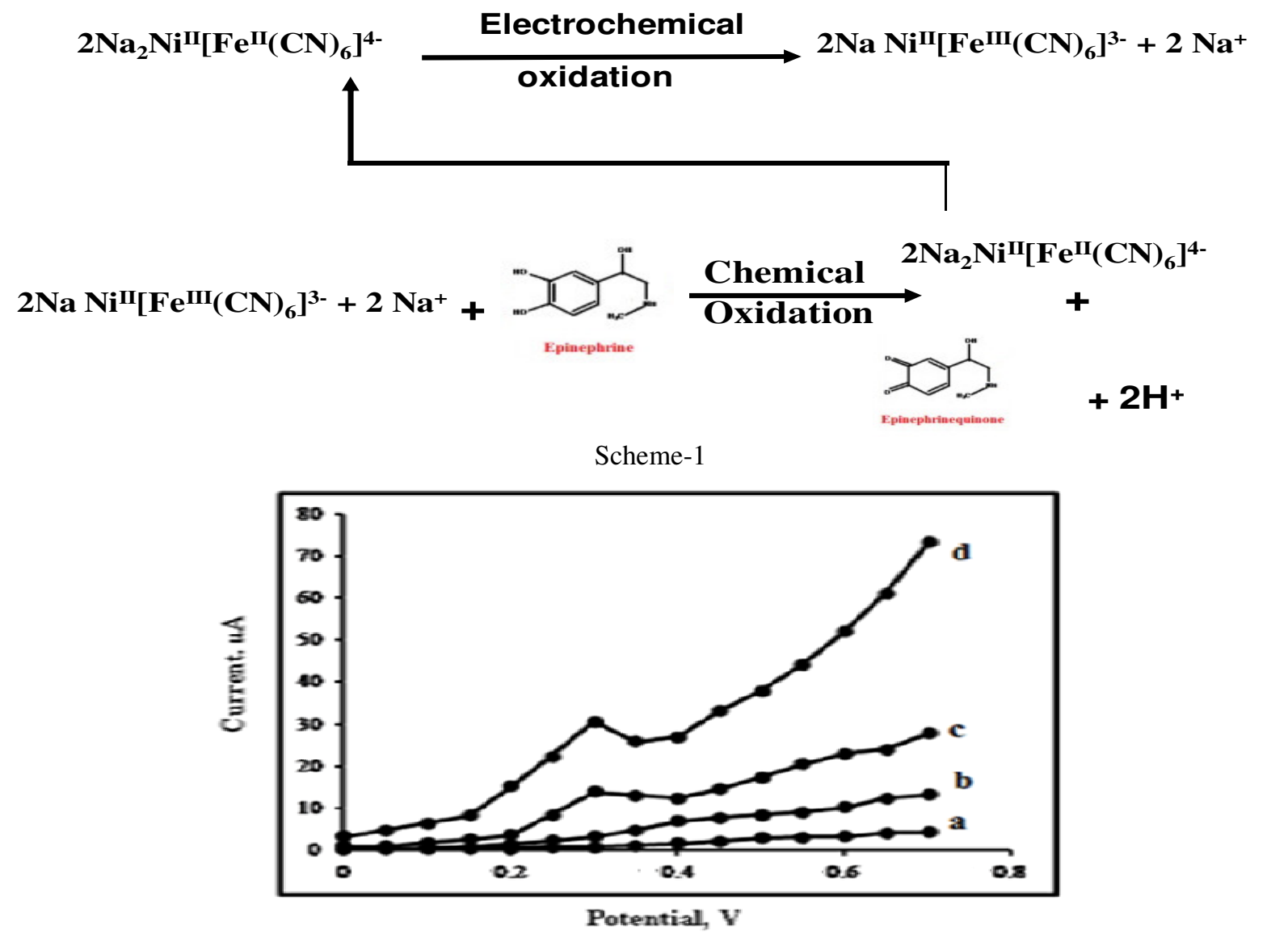

Fig.-6: Hydrodynamic Voltammograms of (a) Bare Electrode, (b) 2.03 X 10-7 M of Epinephrine at Bare (c) Modified (d) 2.03 X $10^{-7} \mathrm{M}$ of Epinephrine at MWCNT/Nihcf Modified Electrode. Scan Rate: $20 \mathrm{Mvs}^{-1}$ 


\section{Chronoamperometry}

Amperometric measurements were performed with the MWCNT/Cys/NiHCF modified electrode by setting the potential at $0.3 \mathrm{~V}$. Figure- 7 shows the program for various concentrations of Epinephrine at the modified electrode. Distinct current retort on Epinephrine was obtained at the modified amperometric sensor. Plots of the catalytic current samples at a preset time as a task of Epinephrine concentration additional to the application of potential step is shown in the (Fig.-7). The reaction occurring on the modified electrode is extremely rapid in triumph an energetic equilibrium upon every addition to the sample. The step-wise increment is the same in each step. Linearity was observed for the concentration range of $2.03 \times 10^{-7}$ to $2.46 \times 10^{-3} \mathrm{M}$ with the correlation coefficient of 0.9999 .

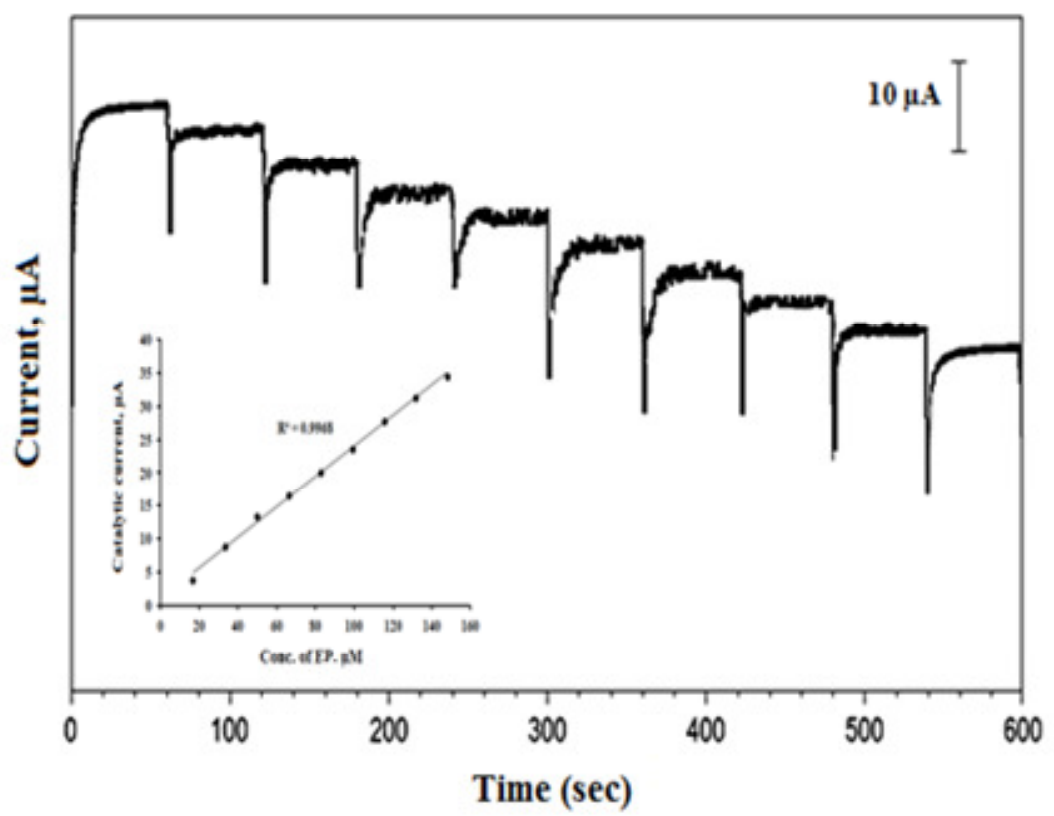

Fig.-7: Amperometric Retort of The MWCNT/Cys/Nihcf Modified Matrix For The Addition Of 0.1 Ml Of $0.01 \mathrm{M}$ Epinephrine In $0.1 \mathrm{M} \mathrm{Nano}_{3}$, Working Potential: $0.3 \mathrm{~V}$.

\section{Interference Study}

The major interfering substrates in EP determination are dopamine (DA) and ascorbic acid (AA). As the differential pulse voltammetry was more sensitive, it was employed for the selective determination of EP in the presence of DA and AA. Figure- 8 shows the differential pulse voltammograms for the oxidation of different concentrations of EP in the presence of $1 \mathrm{mM} \mathrm{DA}$ and AA at the modified electrode. As the electrode is coated with Nafion, a negatively charged polymer, it repels AA, DA and EP alone to reach the electrode surface. The result indicates that the present sensor favors the determination of EP at lower oxidation potential.

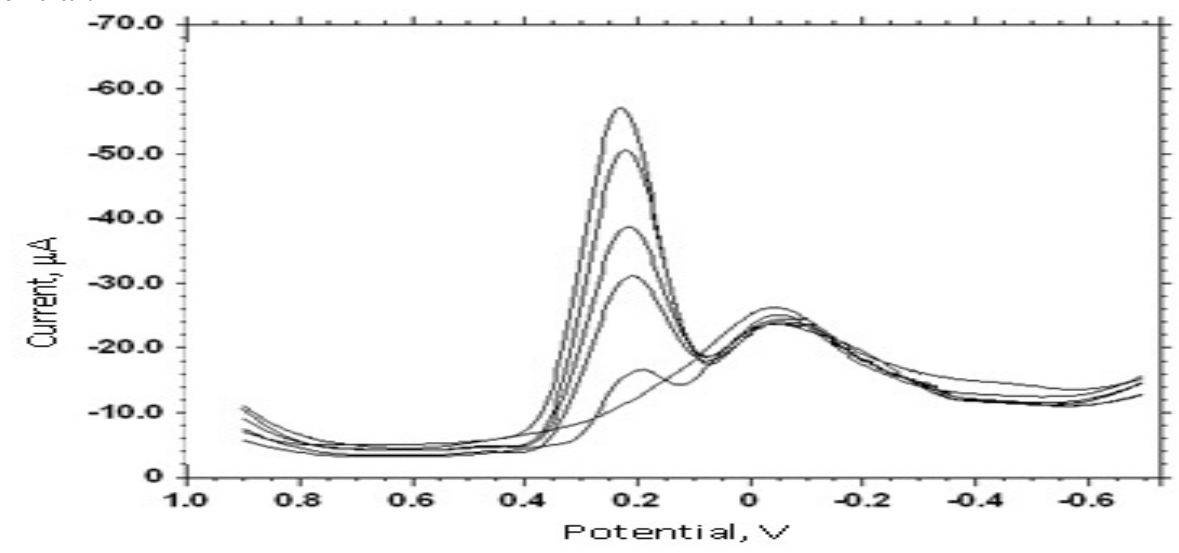

Fig.-8: Differential Pulse Voltammogram of EP Oxidation at Various Concentrations in the presence of 1mm DA and AA Using MWCNT/Cys/Nihcf Modified Electrode. 
RASĀYAN J. Chem.

Vol. 12 | No. 4 |1985 - 1991| October - December | 2019

\section{CONCLUSION}

The present investigation on MWCNT/Cys/NiHCF modified electrode was fictitious for Epinephrine sensor through electrochemical instruments like cyclic voltammetry, hydrodynamic voltammetry and flow injection analysis. The peak current of Epinephrine has improved significantly and the oxidation peak shifted towards positive potential with MWCNT/Cys/NiHCF film. Its reward, such as effortless, susceptible, hasty and precise, was established by Epinephrine determination.

\section{ACKNOWLEDGMENT}

The authors thank Chemistry Department, Cauvery College for Women, Thiruchirapalli, Tamilnadu, India, for providing necessary research facilities.

\section{REFERENCES}

1. M. Gavalas, A. Sedana S. Metcalf , J Accid Emerg Med., 15 (1), 96(1998), DOI: 10.1136/emj.18.5.328.

2. FER. Simons, ZH.Chad, A. Norman and K.J. Simons, J. Allergic and Clinical Immunology., 109 (1), 337 (2002), DOI:10.1067/mai.2002.120758.

3. J. Soar CD. Deakin, JP. Nolan et al., Resuscitation., 67(1), 135(2010), DOI:10.1016/j.resuscitation.2010.08.015

4. J. Bousquet, RF. Lockey, H.J. Malling, World Health Organization Position Paper., 102 (1), 1 (1998), DOI:10.1016/S0091-6749(98)70271-4

5. G. Sivasankari, C. Priya and S. Sriman Narayanan, International J. of Pharma. and Bio.Sci, 2,(1) 188 (2012), DOI:10.22376/ijpbs

6. C. Priya, G. Sivasankari and S. Sriman Narayanan, J. Colloids and Surfaces B: Biointerfaces., 97 (4), 90 (2012), DOI: 10.1016/j.colsurfb.2012.04.004.

7. G. Sivasankari, S. Boobalan, P. Santhi and S. Dhanalakshmi, J. Glob. Res. and Dev. Eng., 9(1), 39 (2016)

8. G Sivasankari, D Rajalakshmi and S Boobalan, J. Chem. and Pharm. Res., 9(12), 119(2017)

9. G Sivasankari, S Boobalan and D. Deepa,J. Asian. Pharm. and Tech., 8(2), 47(2018), DOI: 10.5958/2231-5713.2018.00013.2.

10. J. Joseph, H. Gomathi, G.P. Rao, , J. Electroanal. Chem., 431(2), 231(1997), DOI: 10.1016/S00220728(97)00169-1.

11. A. Dostal, B. Meyer, F. Scholz, U. Schro“der, A.M. Bond, F.Marken, S.J. Shaw., J. Phys. Chem., 99 (7) ,2096(1995), DOI: 10.1002/elan.200302942.

12. A. Dostal, M. Hermes, F. Scholz, J. Electroanal. Chem., 451(4), 133(1996), DOI: 10.1007/978-3319-10843-8.

13. M. Hermes, Diplom. thesis, Department of Chemistry ,Hamburg, Universität Münster HUB, (1996)

14. F. Scholz, A. Dostal, J. Angew Chem., 107(23), 2876 (1995), DOI: 10.1007/s100080050157.

15. M. Shporer, G. Ron, A. Loewenstein, G. Navon, J. Inorg. Chem.4(3), 361 (1965), DOI: 10.1021/ic50025a022.

16. H. Dai, J. Phys. World, 332 (3), 321 (2000), DOI: 10.1063/1.1408274.

17. A.N. Frumkin, O.A. Petry, N.V. Nikolaeva-Fedorovich, J. Electrochim. Act., 8(2), 177(1963), DOI: 10.1016/j.electacta.2017.12.062.

18. P. Xiang Hou C. Liu H.Cheng, Carbon., 46(15), 2003 (2008), DOI: 10.1016/j.carbon.2008.09.009.

19. L.H. Guan, Z.J. Shi, M.X. Li, Z.N. Gu, Carbon., 43(13), 2780(2005), DOI:10.1002/smll.201401034.

[RJC-5430/2019] 